\title{
3. Analytical game design: Game-making as a cultural technique in a gamified society
}

\author{
Stefan Werning
}

\begin{abstract}
This chapter aims to show how designing and modifying games is becoming a "cultural technique" (Kramer and McChesney 2003) similar to reading or writing, and an important requirement for active citizen engagement in an increasingly ludified society (Raessens 2006). For that purpose, "constructionist gaming" (Kafai and Burke 2015), i.e. game co-creation, is situated among other critical playing practices like theorycrafting. Numerous examples, from early Flash games created as commentary on the 2003 invasion of Iraq to game jams such as the 2013 GeziJam, demonstrate how grassroots game development can establish ephemeral public spheres for playful citizen intervention. Finally, the chapter outlines analytical game design as a conceptual framework for incorporating these principles into media studies research and educational practice.
\end{abstract}

Keywords: Analytical game design, constructionist gaming, playful citizenship, cultural techniques, game design literacy

Media technologies are connected to the concept of citizenship in manifold ways and the rapid changes in media technologies are one important reason why, analogously, the notion of citizenship is rapidly changing. One aspect of citizenship in this context is the capacity to express and discuss one's opinion. In that regard, media institutions like public service broadcasters have been interpreted as an "embodiment" of the notion of the public sphere, i.e. a physical, social or other kind of space for discourse among citizens, thereby becoming a "technology of citizenship" themselves (Nolan 2006, 226).

Glas, R., S. Lammes, M. de Lange, J. Raessens, and I. de Vries, eds. 2019. The Playful Citizen. Civic Engagement in a Mediatized Culture. Amsterdam: Amsterdam University Press. DOI: $10.5117 / 97894629845^{23} / \mathrm{CHO} 3$ 
This aspect is directly related to the notion of performativity or "performative publicness," which includes "affective and playful dimensions" of social interaction as well as, drawing on the notion of performative utterances, the constitution of "civil selves" (Chouliaraki 2012, 2-4).

A conceptualization of citizenship that is more specifically suited to the premise of this chapter is the notion of 'silly citizenship,' which foregrounds aspects of play, "struggle," (Hartley 2010, 233) and contested identities. Accordingly, citizenship as a concept, an abstraction, has had different connotations in various discourses since its emancipation from the confines of the city in the nineteenth century. Negotiating this "conceptual baggage" and reaffirming the validity of citizenship, according to Hartley, requires a playful attitude (Ibid., 234).

Social spaces that would afford the performance of citizenship are increasingly permeated by layers of software (Kitchin and Dodge 2011) that provide new opportunities, but also come with new types of requirements. Emergent political parties such as the Piratenpartei (pirate party) in Germany or the Partido de la Red (net party) in Argentina, which represent common citizen sentiments on the level of polity, not only practically draw on software tools like Liquid Democracy (Litvinenko 2012) and DemocracyOS, but also use programming as a conceptual model of active citizenship and software as a metaphor of how a modern society should function. Douglas Rushkoff aptly summarized this situation using the moniker "program or be programmed" (2010), a phrase that emphasizes the urgency of the situation and the (assumed) lack of a third option. The degree to which the logic (or at least the rhetoric) of program code is gradually becoming embedded into public discourse is reflected by the fact that software has become a metaphor for political organization and for the role of the citizen within it.

However, with the increasing adoption of gamification principles and mechanisms at all different levels of society -including education, corporate training and even tentatively in parts of the public sector (Wood 2013; Asquer 2014), being an independent citizen arguably requires not only basic knowledge of software and programming, but also of games and game design.

Already in the 1950s, sociologist Norton Long proposed that we understand the local community as an ecology of games (Long 1958), a concept that has been repeatedly used to investigate policies even until the present (e.g. Lubell 2013). From this perspective, the manifold dependencies between different sectors of society, including "banking, newspaper publishing, contracting [and] manufacturing" (Long 1958, 251), can be understood as players involved in multiple, partially overlapping games at the same time. While Long focuses on the rationales of the 'players' that, in some cases, 
have to negotiate different roles, his approach is also relevant from the perspective of the game designer, i.e. the policymaker, 'modeling' society as an assemblage of interlocking games.

From this angle, which has become only more plausible in light of the gamification debate, this chapter argues that citizens not only need to be able to assume the player's perspective, but the game designer's as well. They must strive not just to master a given game, but to understand it in terms of its contingencies and potential alternative 'design choices.' One example where this expanded perspective becomes particularly tangible is the ideology of startup ecosystems; software developers adopting the entrepreneural 'persona' by definition use digital technology to at least partially rewrite the rules of a particular social 'game' (e.g. Uber for urban mobility and Airbnb for accommodation) rather than playing the traditional game more effectively.

With reference to 'end users,' the notion of "retail hacking” (Schwartz 2010) already tentatively indicates how an applied understanding of game design helps to address socio-economic issues. The term refers to the fact that consumers (particularly from low-income families that would otherwise have problems affording the amenities of everyday life) gradually combine and exploit the manifold coupon and rebate schemes offered by large retailers (originally for their own economic benefit) to multiply their savings and to continue participating in society despite their financial troubles. While this situation is not explicitly game-like, the terminology and rhetoric used by retail hackers ${ }^{1}$ indicates that they construct (or 'design') their consumption practices as a de-facto game with the goal of maximizing value-for-money. For instance, techniques like 'stacking' and 'rolling' are — both conceptually and terminologically — reminiscent of power gaming and 'combo' systems. By taking rules from different 'sub-games' (the individual rebate schemes), they build a new game that, according to their self-perception, maximizes their agency as citizens and economic subjects.

Thus, the goal of this chapter is to show how, similar to reading, writing, and communicating, designing and modifying games is becoming a cultural technique' (for an overview of the term and its connotations see Kramer and McChesney 2003) for active citizen engagement in an increasingly ludified society (Raessens 2006, 2014). In terms of citizenship, 'cultural techniques' constitute the required skills to participate in public spheres and in social negotiation processes. More broadly, the term refers to culturally

1 The term 'hacking', at least outside of criminal activities, already exhibits a conceptual link to a playfully irreverent disposition (Stober, Walz, and Holopainen 2013). 
formative practices, which are practices that afford cultural production, exchange and archiving/remembrance in the first place, but also develop their own characteristic quasi-cultural contexts over time. For instance, even though he does not explicitly use the term, Jay Bolter shows how speech and, more broadly, even thought processes are significantly influenced by the materiality of writing and the "writing space" (2001). A similar argument can be made for digital games as well; that is, if written words serve as an interpretive filter for oral rhetoric, 'writing' games can be conceived of as a filter for playing and interpreting games, for not just thinking about games, but also thinking 'through games'.

The following section will prepare a more detailed understanding of game-making as a cultural technique by looking at how playing practices have turned games into cognitive tools and how game creation itself is becoming a playful activity.

\section{From productive playing practices to playful game production}

With the increasing abundance of games available and the increasing differentiation of player audiences, it comes as no surprise that, over time, playing practices have become much more diversified, going well beyond the initial aim of 'mastering' the game. More specifically, many of these practices can be understood as productive, even genuinely 'analytical.' Even in the early days of the field of game studies, the "demystification" (Friedman 1999) of the (digital) game as a system stood out as a central motivation. Ted Friedman furthermore usefully points out that -in opposition to film reception, one might add - players approach identification from a procedural perspective; in the case of SimCity (Maxis 1989), for instance, they switch between different identificatory positions (mayor, treasurer, head of police, etc.) to interpret the simulated system from different angles rather than build an 'empathetic' relationship with any of them.

More recently, theorycrafting has been investigated (e.g. Paul 2011) as an increasingly formalized set of playing practices aimed at understanding the rule system of a game, down to its variables and algorithms, by strategically testing and documenting the observable systemic behavior rather than simply 'playing to win.' It is important to note that this highly idiosyncratic and seemingly arbitrary behavior is intrinsically political, it represents a more or less conscious attempt at challenging (albeit not really altering) the political economy of the games industry. In that sense, i.e. in terms of its 'quasi-political' agenda, theorycrafting is comparable to spoiling (Jenkins 
2006), a more well-studied, subversive practice of television reception. Moreover, the games that theorycrafters play are often 'virtual worlds' (usually MMORPGs or hybrid games like Destiny (Bungie 2014)), continuously changing systems that 'encourage' players to experiment with policies and more or less formalized patterns of social control.

Theorycrafting is not the only recent playing practice that can be considered intrinsically 'analytical,' though. For instance, in-game photography (e.g. Poremba 2007), the act of taking pictures (or, more precisely, screenshots) in digital games rather than playing by the rules, can be understood as analytical on several levels. First, it draws on the player's photographic gaze to produce a new understanding of the virtual environment according to the rationales of photography such as mise en scène and framing. Second, based on the types of 'photographs' taken, it appears that this practice allows for players to re-investigate established pictorial genres such as landscape photography, still life, and portraits, with regard to seemingly anachronistic notions like aura (Duttlinger 2008). ${ }^{2}$ Finally, professional in-game photographers adopt an analytical stance in that they document the parameters in which a photo is taken, thus allowing others to reflect on the 'material' contingencies, develop a media-reflexive view, and re-produce or modify selected aesthetic strategies.

While playing practices thus become more 'productive' and analytical over time, inversely, game development can also increasingly be understood as a genuinely playful and simultaneously analytical, knowledge-producing practice. This play element obviously is most visible in independent game development, which is internally organized through game jams (Guevara-Villalobos 2011), competitions to create games within self-imposed constraints, ${ }^{3}$ rather than hierarchy and technical specialization as well as standardization. However, professional game development also embraces aspects of playfulness. For example, Birdwell describes how the game Half-Life (Valve 1998) was created by taking apart the original prototype and, for instance, requiring designers to take an arbitrary set of parts and recombine them in novel, fun ways (1999). Moreover, Van der Graaf illustrates how Linden Lab, the developer of Second Life (2003), introduced a virtual currency called "love scores" $(2012,486)$ that employees could receive from

2 A prominent archive of highly sophisticated in-game photographs can be found in Harris (2018).

3 Apart from the set theme that every game jam participant has to follow, the Global Game Jam offers a selection of 'modifiers', additional thematic requirements that allow for contestants to choose their own 'difficulty level'. 
other colleagues or award to their colleagues, thereby incentivizing them to help each other out; even though 'love' is paid out as a bonus each quarter, this is still a mostly tongue-in-cheek, highly idiosyncratic way of fostering group identity through 'playful' interaction. On that note, the following section will explore what kind of knowledge game-making can produce.

\section{Between ludoliteracy and algorithmic literacy}

One of the first steps toward game design becoming a 'cultural technique' is Adobe Flash, an authoring system that, while originally developed for designing interactive animations, has been among the first tools that opened up game creation to a broader, more mainstream audience. Adobe Flash has already been studied from a software studies perspective (e.g. Sorapure 2006), for example with regard to how it affects writing practices despite being originally intended primarily for multimodal composing. However, for the purpose of this argument, Adobe Flash is particularly relevant because it allowed for accelerating the creation of simple, digitally sharable applications.

Take, for instance, the Flash games created in response to the US invasion of Iraq in 2003, which journalist Clive Thompson described as the "newest form of social comment" (Thompson 2002). Many of the games Thompson describes convey a rather blatant (only in some cases "procedural") rhetoric (Bogost 2007, 52) or use pop-cultural and game-specific references and metaphors to connote the events of $9 / 11$. However, a few outstanding examples such as New York Defender (Stef \& Phil 2001) can even be described as positively "persuasive" (Ibid., 59ff.) and at least enable players to potentially reassess the subject matter using genuinely game-specific means.

Apart from easy-to-use functions for collision detection and player interaction via mouse, keyboard, and gamepad, the most notable affordance of Adobe Flash as a tool to promote game creation was the Flash Player, a browser plug-in that quickly became ubiquitous and facilitated the distribution of Flash-enabled games. In terms of game development as a 'cultural technique,' this is relevant for multiple reasons. The accumulation of Flash games on platforms like Newgrounds shifted the focus from the often still trivial individual games toward the sheer quantity of games and, thus, made the amateur game developer community 'visible' for the first time, both for a mainstream audience and its own members. Put differently, the Flash game websites act as platforms that employ a set of socio-technical mechanisms (Niederer and Van Dijck 2010) to foster group identity, to allow 
the community to grow organically, and to incentivize peer review in addition to learning from one another. For instance, the rating system on a site like Newgrounds allows newcomers to already earn some recognition without having to compete on 'equal ground' with more established developers and still constitutes an attention economy that motivates veterans to push the envelope and aim for ever higher scores.

The gradual 'demise' of Flash (Salter and Murray 2014) is an important event in software history and culture. However, for the purpose of this chapter, it is even more noteworthy because existing, more dedicated gamecreation tools like RPG Maker (1988-), Game Maker (1999-), and entry-level ${ }_{3} \mathrm{D}$ engines like Unity ${ }_{3} D$ (2005-) eventually became the first point of contact with algorithmic thinking and scripting for media users that grew up with video games, a fact that indicates the increasing convergence of ludoliteracy (Zagal 2010) and algorithmic literacy. As indicated above, creating games, both from an amateur and independent game perspective, is becoming intrinsically playful; at the same time, game design - conceptualizing a given subject matter by way of rule systems-becomes intrinsically technical, shaped by material affordances and constraints. The following section will elaborate on how these developments are relevant in terms of citizen engagement and politically mindful media use.

\section{Analytical game design as playful citizen engagement}

Experimental games already exhibit clearly observable tendencies to use digital games as a medium of socio-political expression. For example, Twine (2009-) is a freely available, highly accessible, and thus popular tool that allows for creating experimental text-based games. At the same time, it notably enhances the use of game design as a form of public expression because it increases the thematic and rhetorical diversity of digital games, allowing for the expression of otherwise marginalized viewpoints. Unsurprisingly, some of the most notable Twine games tackle issues like gender identity and subcultural sensibilities, which otherwise rarely have a place in either commercial or independent game design.

Furthermore, as amateur game developers become more confident in the use of tools as well as procedural rhetoric, contributions to game jams increasingly address socially relevant or even political themes. For example, the Game of Politics (Telnov et al. 2012), created for the Global Game Jam 2012, is a deck-based card game about political decision-making and the election process. Conceptually very similar, but developed three years later, 
Vox Populi (Lewis and Henley-Roussel 2015) is also a game based on physical playing cards, in which, "[a]s your party's campaign organizer, you must forgo every principle, make any deal you can, and screw over everyone else in order to grasp the reins of power." In comparison, Doctrine (Mielczarek et al. 2014) tackles the broader issue of divergent political ideologies and employs less 'naturalistic' design mechanics, using colored filters worn as headgear and differently colored messages to indicate how ideologies can make a person 'blind' toward non-conformist opinions.

Smaller game jams are occasionally even 'designed' and leveraged as tools for political participation themselves. For instance, the GeziJam was held in June 2013 to support and raise awareness of the protesters trying to stall the destruction of the Taksim Gezi Park in Istanbul. The conceptually related \#JamForLeelah reflected on the suicide of Leelah Alcorn in December 2014 and challenged participants to tackle the issue of transgender sensibilities through the creation of games. In some cases, game developers are trying to monetize this awareness and create games to raise funds for socio-political causes. For instance, the game Kubba was created by Ahmed Abdelsamea (2012), an Egyptian indie designer, to generate revenue benefiting the refugees of the Syrian civil war (Curley 2012). The game mimics the more or less iconic Western game franchise Cooking Mama (Office Create 2006), challenging players to prepare the eponymous Syrian dish, Kubba. The game is a variation of the earlier Flash game Ta'mya (2012); yet, while the original has English text and is available on Kongregate, a website hosted by United States games retailer GameStop, Kubba was only playable on the now-defunct Arabic equivalent GameTako.

Yet, most of these experimental games usually operate according to the logic (or, with Michel Foucault, the dispositif) of art rather than education. They all have a 'product form,' a defined beginning, middle, and end including some sort of menu system. The aforementioned game jams exhibit several structural similarities to the system of festivals and awards that constitutes an important infrastructure for art in its currently practiced sense and, in itself, is unmistakably game-like (English 2005). Games developed by scholars or 'reflective' industry practitioners are sometimes even commissioned 'as art,' i.e. they are ordered and paid for by institutions formally or informally related to the 'art world' (Becker 1982) or publishing industry. Ian Bogost's Simony (2012) and Jason Rohrer's Game Design Sketchbook experiments are but two prominent examples. Second, they are sometimes displayed 'as art' in the context of a thematically integrated exhibition; again, Bogost's Simony as well as many games by Tale of Tales clearly illustrate this principle. Third, they are often discussed and framed in terms of art discourse, focusing 
on common tropes such as the creator persona (e.g. Rohrer's Gravitation (2008)), the subversion of expectations, or a media-reflexive habitus (e.g. Bogost's Cow Clicker (2010)).

In comparison, the concept of Analytical Game Design, which is phenomenologically explored at the Utrecht Game Lab, defines a methodological framework to translate the notion of game-making to the educational domain and, as a potential second step, to political participation. The concept draws on the Kuleshov experiments, a series of film vignettes - often only a few seconds long — produced by directors like Kuleshov and Pudovkin in the 1920 , which systematically explore the expressive 'vocabulary' of film as a then-new medium (Prince and Hensley 1992). While these experiments are still acknowledged for their aesthetic values and originality, it is important to note that they originated in an experimental culture of film-making; thus, considering the Kuleshov experiments and the countless re-creations that have been created over time, both by film students and acclaimed directors, it appears that the individual experiment does not primarily create knowledge, but instead the process of creating and comparing multiple variations on the same theme and of sharing one's own interpretation by playfully remixing it. ${ }^{4}$

Adhering to these principles, 'analytical' game experiments as defined by the Analytical Game Design framework are:

- vignettes, not 'complete' games;

- built on existing media and cultural studies research;

- intended to test hypotheses and challenge user preconceptions;

- easily modifiable and remixable;

- an ongoing process by constituting a 'dialog' with the enabling technologies ascognitive tools;

- usually abstract in terms of audio-visual detail and semantics;

- published in a way that affords discussion and multiplicity;

- $\quad$ and (optionally) utilizing analytics for non-commercial purposes. ${ }^{5}$

Few existing games can be considered 'theory-driven'; for instance, while Dan Pinchbeck has implemented some of his academic inquiries into first-person gaming and "ludic manipulation" (2009) in games like Amnesia: The Dark

4 Looking up the Kuleshov experiment on YouTube provides an overview of the manifold ways in which the same experiment has been interpreted-by famous directors and film students alike-over the years.

5 For more detailed information, see the slides of a panel on the topic, organized at the 2016 DiGRA/FDG conference in Dundee (Werning 2016). 
Descent (Frictional Games 2010), other games by the same author/company are only belatedly reflected upon, for instance in terms of environmental storytelling (Pinchbeck 2008). Will Wright's SimEarth (Maxis 1990), a later instalment in the franchise started by SimCity, is one of the few games based on a theory, the highly contested, but still influential Gaia hypothesis (Bogost 2006,167 ) proposed by James Lovelock and co-developed by Lynn Margulis in 1972 and beyond. The hypothesis holds that organisms and inorganic matter on Earth organize to form a self-sustaining complex system; thus, it proposes a set of relationships between co-existing species and a number of system variables such as global temperature, the amount of oxygen in the air, or salt in the oceans. The model is conceptually ideally suited to formalize activities on a global scale for use in a video game, particularly given the technological constraints in the early 1990s. The game arguably not only presents an 'interpretation' of and commentary on the hypothesis, but it also uses it as part of a particular rhetoric, which is - with Bogost - a persuasive strategy.

The notion of Analytical Game Design aims for an even more direct relationship between theoretical background and ludic implementation. For example, Seymour Chatman famously analyzed different modes of narrative in literature and films with a close comparative reading of Guy de Maupassant's Une partie de campagne and Jean Renoir's 1936 film adaptation (Chatman 1980). Chatman proposes a set of categories for his analysis, including concepts such as description vs. assertion (128), ambiguity (132), and focalized narration as well as evoking the reader's perceived complicity with the morally dubious disposition of the narrator (133). While no games exist that systematically explore these categories, ${ }^{6}$ designing game experiments would be a fruitful way to tackle these questions and to 'translate' Chatman's approach of close-reading to (digital) games. The inherently playful quality of this approach is acknowledged by Stephanie de Smale, who expands on the concept and reads analytical game experiments against Theodor W. Adorno's notion of the essay as form $(2016,4)$.

While the previous example pertains more to representations of individual perceptions, the same can be done on a broader scale, including representations of social and cultural phenomena. Simulation games like the aforementioned SimCity or Civilization (MPS Labs 1991) exhibit interesting cultural stereotypes through their attempts to express common perceptions given the

6 This statement might have to be relativized a bit, as games like Gone Home (The Fullbright Company 2013) for instance can be interpreted as playing with the 'mode' of description. However, no games do so in a truly systematic and iterative manner. 
characteristic constraints of their rule systems. For example, while religious buildings have been implemented in Civilization as 'tools' to pacify discontent citizens, later instalments like Civilization $I V$ and $V$ (Firaxis Games 2005, 2010) systematically elaborate on the concept, repeatedly altering the intrinsic rule bias. In that sense, consecutive instalments in the same franchise and especially player-created modifications, which alter the game's procedural rhetoric and introduce multiplicity instead of one authoritative set of game rules (Werning 2017), can be understood as intrinsically 'experimental' in that they modify parameters and processes, thereby making them observable and accessible for discussion through the players.

To summarize, games and the playful wrestling with (often self-imposed) constraints have been used as a tool to overcome established patterns of thinking. In the context of artistic production, this approach has been formalized by collectives like Oulipo (Andrews 2012), but it can also be observed in the aesthetic principles of the Dada movement (Prager 2013), or in the work of composers like John Cage and John Zorn. Toy designer Shimpei Takahashi demonstrated the principle in a 2013 TEDxTokyo presentation using examples of his own. Ideally, using games as a conceptual reference point, the same approach can be applied in contemporary socio-political contexts, in which problems regularly arise from applying standardized thinking to new types of challenges (which is, as McLuhan argued, because "politics offers yesterday's answers to today's questions"; quoted from Genosko 2005, 235).

\section{Conclusion}

The goal of this chapter has been to demonstrate how, not least through novel production and distribution tools like Unity ${ }_{3} D$ and itch.io, game-making is gradually developing into a cultural technique and an opportunity for citizens to understand and shape their social environment. Thus, returning to Rushkoff (2010), the extension of 'program or be programmed' cannot just be 'play or be played'; instead, being able to (co-)create games oneself is an important next step to altering the power relations built into the contemporary gamification of society.

Since this chapter was designed to be exploratory, rather than focusing on just one particular case, many issues could only be touched upon and require further investigation. The role of game distribution websites constitutes only one fruitful opportunity for further research. For instance, while platforms like Newgrounds arguably do not constitute a proper 'public sphere' in the sense of Habermas, they can alternatively be understood as 'third places.' 
The term, which Ray Oldenburg originally coined to describe hybrid spaces between home and work environments, such as cafés and community centers, has already been applied to online games themselves (Steinkuehler and Williams 2006), but the concept could also be brought to fruition to analyze the functions of game distribution platforms as sites of mediated citizen engagement and game-based public discourse. ${ }^{7}$

A second way to extend the perspective outlined above would be to go beyond actual game creation. For instance, research on war games on the corresponding online forums indicates that, even without the technical means to change them, players intrinsically interpret and discuss digital games in terms of their design contingencies, and therefore their potential alternatives. For instance, players of America's Army (United States Army 2002) request and discuss the inclusion of new weapons based on their experience with televised documentaries (Werning 2009, 318). From that angle, modding (the modification of commercial games, often using freely supplied tools) constitutes an interesting hybrid case. For instance, one Civilization V mod called Emigration includes ‘emigration' as a new gameplay mechanic, which addresses the increasing mobility of citizens both within a country and across borders. The mod can be understood as a comment on the political bias of the original game because its rules incentivize players to 'use' emigration as an offensive strategy (“[d] evelop your empire and your rival's citizens will leave their homeland for your prosperous country"). ${ }^{8}$ Another mod for the same game called FIFA World Cup Host Resolution even delivers a more targeted 'message' by utilizing Civilization $V$ to 'expose' FIFA's intrinsic system of power by introducing 'migrant workers' as new unit types. While the host game does not allow for a very naturalistic rendering of the FIFA context, particularly the effort and inevitable inconsistencies of trying to 'express' this system under the constraints of the game's modding tools spark controversy and necessitate a thorough, critical engagement with the subject matter at hand. For good reason, serious games like the Democracy series (Positech Games 2005-) have been developed with mod-ability in mind, both to keep the game relevant over a longer period of time and to alleviate the discrepancy between 'players' and 'designers'.

Finally, a culturally comparative perspective on game creation and the notion of 'cultural techniques' would be a useful extension of the argument presented in this chapter. For instance, the developer of the aforementioned

7 One need only look at the plethora of (still often mundane but increasingly reflective) games created as 'comments' on contemporary elections, see Newgrounds (2018).

8 See the 18 May 2013 update in the change notes of the mod (Valve 2018). 
Flash game Kabba argues that "[p]olitical activism is common in Arabmade indie games" (Johnson 2012). This suggests that 'collective' or at least culturally formative experiences can have a profound impact on game creation, a hypothesis that would by definition substantiate the claim that game-making already constitutes a 'cultural' technique.

\section{References}

Abdelsamea, A. 2012. Kubba. [browser]. GameTako. Game.

Andrews, C. 2012. Constraints, poetry and play in Jacques Roubaud's Parc Sauvage. Australian Journal of French Studies 49 (2): 142-152.

Asquer, A. 2014. Not just videogames: Gamification and its potential application to public services. In Digital public administration and e-government in developing nations, ed. E. F. Halpin. 146-165. Hershey, PA: IGI Global. Becker, H. S. 1982. Art worlds. Berkeley, CA: University of California Press. Birdwell, K. 1999. The cabal: Valve's design process for creating half-life. Gamasutra. The Art \& Business of Making Games. http://www.gamasutra. com/view/feature/3408/the_cabal_valves_design_process_php.

Bogost, I. 2006. Videogames and ideological frames. Popular Communication $4(3): 165-183$.

-. 2007. Persuasive games: The expressive power of videogames. Cambridge, MA: The MIT Press.

-. 2010. Cow Clicker. [Facebook]. Ian Bogost. Game.

-. 2012. Simony. Museum of Contemporary Art, Jacksonville. Multimedia artwork.

Bolter, J. D. 2001. Writing space: Computers, hypertext, and the remediation of print. New York: Routledge.

Bungie. 2014. Destiny. [multiplatform]. Activision. Game.

Chatman, S. 1980. What novels can do that films can't (and vice versa). Critical Inquiry 7 (1): 121-140.

Chouliaraki, L., ed. 2012. Self-mediation: New media, citizenship and civil selves. London: Routledge.

Curley, N. 2012. GameTako launches online game to benefit Syrian refugees. Wamda. http://www.wamda.com/2012/o7/gametako-launches-online -game-to-benefit-syrian-refugees.

De Smale, S. 2016. Game essays as critical media and research praxis. In Proceedings of the first international joint conference of DiGRA and FDG, Dundee, August 1-6, 2016. http://www.digra.org/wp-content/uploads/ digital-library/paper_2351_revised.pdf. 
Duttlinger, C. 2008. Imaginary encounters: Walter Benjamin and the aura of photography. Poetics Today 29 (1): 79-101.

English, J. F. 2005. The economy of prestige: Prizes, awards, and the circulation of cultural value. Cambridge, MA: Harvard University Press.

Firaxis Games. 2005. Civilization IV. [Windows/OS X]. 2K Games/Aspyr. Game.

-. 2010. Civilization V. [Windows/OS X/Linux]. 2K Games/Aspyr. Game.

Frictional Games. 2010. Amnesia: The Dark Descent. [multiplatform]. Frictional Games. Game.

Friedman, T. 1999. The semiotics of Sim City. First Monday 4 (4). http:// firstmonday.org/htbin/cgiwrap/bin/ojs/index.php/fm/issue/view/104.

Genosko, G. 2005. Marshall McLuhan: Renaissance for a wired world. New York: Routledge.

Guevara-Villalobos, O. 2011. Cultures of independent game production: Examining the relationship between community and labour. In Proceedings of Think Design Play: The fifth international conference of the Digital Game Research Association, Hilversum, September 14-17, 2011. http://www. digra.org/dl/db/11307.08157.pdf.

Harris, D. 2018. DET. Deadendthrills. http://deadendthrills.com/game-index. Hartley, J. 2010. Silly citizenship. Critical Discourse Studies 7 (4): 233-248. Jenkins, H. 2006. Convergence culture: Where old and new media collide. New York: New York University Press.

Johnson, J. 2012. Can a Flash game improve the lives of Syrian refugees? Kill Screen. http://killscreen.com/articles/can-flash-game-improve -lives-syrian-refugees.

Kitchin, R., and M. Dodge. 2011. Code/space: Software and everyday life. Cambridge, MA: The MIT Press.

Kramer, S., and A. McChesney. 2003. Writing, notational iconicity, calculus: On writing as a cultural technique. $M L N 118$ (3): 518-537.

Lewis, D. J., and M. Henley-Roussel. 2015. Vox Populi. [Windows]. Global Game Jam. Game.

Litvinenko, A. 2012. Social media and perspectives of liquid democracy: The example of political communication in the Pirate Party in Germany. In Proceedings of the 12th European conference on e-government, Barcelona, June 14-15, 2010, 403-407. Reading: Academic Publishing International.

Long, N. E. 1958. The local community as an ecology of games. American Journal of Sociology 64 (3): 251-261.

Lubell, M. 2013. Governing institutional complexity: The ecology of games framework. Policy Studies Journal 41 (3): 537-559.

Maxis. 1989. SimCity. [multiplatform]. Maxis/Brøderbund/Infogrames. Game. 
—.1990. SimEarth. [multiplatform]. Maxis. Game.

MPS Labs. 1991. Civilization. [multiplatform]. MicroProse. Game.

Mielczarek, G. et al. 2014. Doctrine. [Windows]. Global Game Jam. Game.

Newgrounds. 2018. Searching the games portal for 'election'. Newgrounds. http://www.newgrounds.com/portal/search/games/election.

Niederer, S., and J. van Dijck. 2010. Wisdom of the crowd or technicity of content? Wikipedia as a sociotechnical system. New Media \& Society 12 (8): 1368-1387.

Nolan, D. 2006. Media, citizenship and governmentality: Defining 'the public' of public service broadcasting. Social Semiotics 16 (2): 225-242.

Office Create. 20o6. Cooking Mama. [iOS/Android]. Office Create Corp. Game.

Paul, C. A. 2011. Optimizing play: How theorycraft changes gameplay and design. Game Studies 11 (2). http://gamestudies.org/1102/articles/paul.

Pinchbeck, D. 2008. Dear Esther: An interactive ghost story built using the Source engine. In Interactive storytelling, eds. U. Spierling and N. Szilas, 51-54. Berlin, Heidelberg: Springer Berlin Heidelberg.

-. 2009. Shock, horror? First-person gaming, horror, and the art of ludic manipulation. In Horror video games: Essays on the fusion offear and play, ed. B. Perron, 79-94. Jefferson: McFarland.

Poremba, C. 2007. Point and shoot. Remediating photography in gamespace. Games and Culture 2 (1): 49-58.

Positech Games. 2005. Democracy [Windows/OS X/Linux]. Positech Games/ Tri-Synergy. Game.

Prager, P. 2013. Play and the avant-garde: Aren't we all a little dada? American Journal of Play 5 (2): 239-256.

Prince, S., and W. E Hensley. 1992. The Kuleshov effect: Recreating the classic experiment. Cinema Journal 31 (2): 59-75.

Raessens, J. 2006. Playful identities, or the ludification of culture. Games and Culture 1 (1): 52-57.

-. 2014. The ludification of culture. In Rethinking gamification, eds. M. Fuchs, S. Fizek, P. Ruffino, and N. Schrape, 91-114. Lüneburg: meson press.

Rohrer, J. 2008. Gravitatian. [Windows/MacOS/Linux].Jason Rohrer. Game. Rushkoff, D. 2010. Program or be programmed: Ten commands for a digital age. New York: OR Books.

Salter, A., and J. Murray. 2014. Marking new ground: Flash, HTML5 and the future of the web arcade. In Proceedings of the gth international conference on the foundations of digital games, Liberty of the Seas, Caribbean, April 3-7, 2014. http://www.fdg2014.org/papers/fdg2014_paper_27.pdf.

Schwartz, M. 2010. The coupon rebellion. Wired Magazine 18 (12): 188-193-224. 
Sorapure, M. 2006. Text, image, code, comment: Writing in Flash. Computers and Composition 23 (4): 412-429.

Stef \& Phil. 2001. New York Defender. [browser]. Game.

Steinkuehler, C. A., and D. Williams. 2006. Where everybody knows your (screen) name: Online games as 'third places'. Journal of ComputerMediated Communication 11 (4): 885-909.

Stober, J., S. Walz, and J. Holopainen. 2013. Hacking as a playful strategy for designing artistic games. In Context matters! Proceedings of the Vienna games conference 2013: Exploring and reframing games and play in context, eds. K. Mitgutsch, S. Huber, J. Wimmer, M. G. Wagner, and H. Rosenstingl, 308-321. Vienna: New Academic Press.

Telnov, J. et al. 2012. Game of Politics. [Windows]. Global Game Jam. Game.

Thompson, C. 2002. Dot-columnist: Online video games are the newest form of social comment. Slate, August. http://www.slate.com/articles/ technology/webhead/2002/08/dotcolumnist.html.

United States Army. 2002. America's Army. [Windows/PS4]. United States Army. Game.

Valve. 1998. Half-Life. [Windows/OS X/PS2]. Sierra Studios. Game.

- 2018. Steam community: Emigration: Change notes. Steam. http:// steamcommunity.com/sharedfiles/filedetails/changelog/115134695.

Van der Graaf, S. 2012. Get organized at work! A look inside the game design process of Valve and Linden Lab. Bulletin of Science, Technology \& Society $32(6)$ : 480-488.

Werning, S. 2009. Real wars on virtual battlefields: The convergence of programmable media at the military-civilian margin. Bielefeld: transcript Verlag.

- 2016. DigraFDG2016: From practice-based game research to game design as cultural technique. Slideshare. http://www.slideshare.net/ stefanwerning/digrafdg2016-from-practicebased-game-research-togame-design-as-cultural-technique.

- 2017. Modding as a strategy to (de-)legitimize representations of religion in the civilization franchise. In Participatory digital cultures and contemporary discourses of (de)legitimization, eds. A. S. Ross and D. J. Rivers. London: Routledge.

Wood, C. 2013. Gamification: Governments use gaming principles to get citizens involved. Government Technology. http://www.govtech.com/local/ Gamification-Governments-Use-Gaming-Principles-to-Get-CitizensInvolved.html.

Zagal, J. P. 2010. Ludoliteracy: Defining, understanding, and supporting games education. Pittsburgh, PA: ETC Press. 


\section{About the author}

Stefan Werning is an Associate Professor for Digital Media and Game Studies at Utrecht University. He holds a degree in North-American Studies from Bonn University (Germany), a PhD (2010) in Media Studies from Bonn University and received his habilitation (2014) from Bayreuth University (Germany). Previously, he worked as an Assistant Professor in Bayreuth and Bonn. Stefan has been a visiting scholar (2005) and fellow (2006-2010) in the program in Comparative Media Studies at MIT. He worked in the digital games industry while completing his $\mathrm{PhD}$ research, most notably at Codemasters (2005) and Nintendo of Europe (2007-2009). 